\title{
Possible Differences in some Characteristics of Lightning in the Tropics and in Temperate Latitudes as deduced from Experiments with Lightning Flash Counters (LFC's)
}

\author{
M. L. T. Kannangara \\ Department of Physics, University of Colombo, Colombo, Sri Lanka. \\ (Date of receipt : 03 November 1982) \\ (Date of acceptance : 01 Decernber 1982)
}

\begin{abstract}
The results of an experiment where a 10KHz, V04 Lightning Flash Counter (LFC) and a $10 \mathrm{KHz}, \mathrm{V} 10 \mathrm{LFC}$ were operated together for one year from the 1st July 1981 to the 30th June 1982 are discussed in the light of a previous experiment described in the J. Natn. Sci. Coun. Sri Lanka, $19819(2): 229-249$, where a $500 \mathrm{~Hz}$, V03 LFC and a $10 \mathrm{KHz}$, V04 LFC were operated together for one year from the March 1979 to the 29th February 1980.
\end{abstract}

The two experiments taken together suggest that lightning in the tropics may have two important characteristics, which have not been reported earlier:

(a) the proportion of cloud to ground flash first return strokes, carrying high peak currents may be appreciably lower in the tropics than in temperate latitudes.

(b) intra-cloud lightning flashes seem to contain much stronger and sharper current pulses than hitherto suspected.

Further points of local interest that come out of the two experiments are that the cloud to ground flash lightning density, $\mathrm{N}_{\mathrm{g}}$, in $\mathrm{km}^{2}$ per year in the region round Colombo for the year 1st March 1979 to the 29th February 1980 was about 6.5, whereas for the year 1st July 1981 to the 30th June 1982, it was about 4.5 , and the ratio $\mathrm{Nc} / \mathrm{Ng}_{\mathrm{g}}$ of intra-cloud lightning flashes to cloud to ground lightning flashes for the corresponding years were abcut 8.5 and 9.5 respectively.

\section{Introduction}

In a previous paper, ${ }^{6}$ the counting efficiency for ground flashes of lightning, as a function of distance, for a $500 \mathrm{~Hz}$, VO3 Lightning Flash Counter LFC and a $10 \mathrm{KHz}$, VO4 LFC respectively was deduced from measurements in Colombo, Sri Lanka.

An important feature of this experiment was that all the counts registered by the two counters for a whole year from the 1st March 1979 to the 29th February 1980 were taken into account in the analysis. The counts were taken at three-hourly intervals and a team of 27 aural observers stationed at locations scattered over the island of Sri Lanka were used to obtain reports of thunder (T) occurring at these locations for each three-hour counting period, day and night, throughout the year. The closest stations (CS), reporting $\mathrm{T}$ during each three-hour period was determined and the analysis was made on the counts registered per three-hour period in terms of the CS reporting $T$ during that period. The counting efficiencies of the LFC's as a function of distance were deduced from this analysis. 
The counting efficiency of a VO4 LFC for ground flashes as a function of distance was also determined at Uppsala, Sweden by Cooray ${ }^{5}$ in 1982, where a gated wide band magnetic direction finder system for lightning return strokes, designed by Krider et $\mathrm{al}^{7}$ was used to determine the location and amplitude of a good sample of ground flashes which would register a count on a VO4 in coincidence with the signal recorded on the lightning location system (LLS).

The efficiency curves obtained by the two methods in Colombo and Uppsala respectively, differed. The difference is shown in Figure 1.

An experiment similar to the one described in paper ${ }^{6}$ was performed in Colombo, over the period lst July 1981 to the 30th June 1982, where a $10 \mathrm{KHz}$, V10 LFC was operated together with a $10 \mathrm{KHz}, \mathrm{V} 04 \mathrm{LFC}$. The V10, which will be described in the next section, has characteristics similar to the RSA 10, 10KHz Anderson counter. ${ }^{1}$ From the result of the experiment described in paper, ${ }^{6}$ the performance of the V10 in this experiment could be predicted and checked with the data obtained. Further, this experiment provided a further year's counting data with the V04 from which the validity of the efficiency curve for that counter, obtained in the previous experiment ${ }^{6}$ could be checked.

A number of assumptions were made in the analysis of the data of the previous experiment, presented in paper, ${ }^{6}$ which were based on qualitative Meteorological observational data provided by the Department of Meteorology, Sri Lanka and from personal experience of thunderstorms in Sıi Lanka. For example, it was assumed that thunderstorms would move an average distance of $45 \mathrm{~km}$ toward or away from Colombo during a three-hour counting period. It was also assumed that thunderstorms in Sri Lanka are not of the fiontal type, but that they are thermal and wind confluence storms, which c re generated more or less in isolated areas, more often than not near the foot hills of the central mountain mass in Sri Lanka at a distance of about $60 \mathrm{~km}$ inland from Colombo. Such storms move along relatively narrow fronts. Also it was assumed, largely from personal experience, that an aural observer of $\mathrm{T}$ would on an average record $\mathrm{T}$ if the lightning flash occurred within a distance of $10 \mathrm{~km}$ from him. Small departures from the strict accuracy of these assumptions do not affect the conclusions reached significantly.

One assumption made was that when Colombo was the $\mathrm{CS}$ reporting $\mathrm{T}$, the average distance, $\mathrm{d} \mathrm{km}$, of the closest approach of the storm to the counters was $6.67 \mathrm{~km}$. This is the average distance of a point within a circle of $10 \mathrm{~km}$ radius. However, the annual number of ground flashes within a radius of $10 \mathrm{~km}$ from the counters, $\mathrm{N}_{\mathrm{g}}$ say, and the ratio, $\mathrm{N}_{\mathrm{c}} / \mathrm{N}_{\mathrm{g}}$, of the number of intra-cloud flashes, $\mathrm{N}_{\mathrm{c}}$, which trigger the counters, and $N_{g}$ deduced in that experiment, ${ }^{6}$ is sensitive to the choice of $\mathrm{d} \mathrm{km}$. 


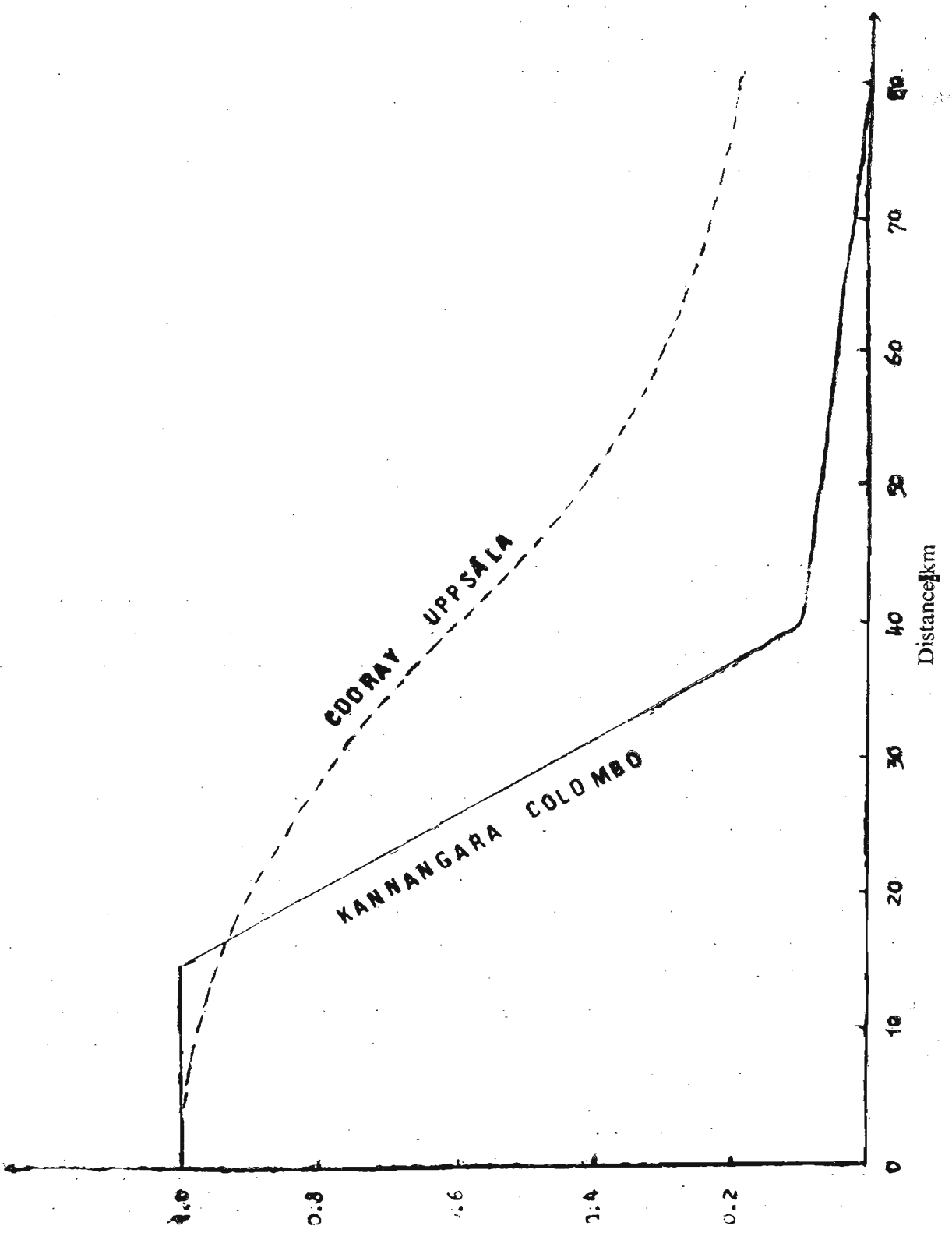

Counting Efficiency of the VO4 for ground flash

Figure 1. The difference in the counting efficiency curves for ground flashes ojtained for a Vod Lightning flash conter in Colombo and in Uppsala. 
Using the counting data of that experiment, ${ }^{6}$ Table 1 shows how $\mathrm{N}_{g}$ and $\mathrm{N}_{\mathrm{c}} / \mathrm{N}_{g}$, and also the estimates of how many intra-cloud flashes would have been counted by each counter over the year, would vary for different assumed values of $\mathrm{d} \mathrm{km}$.

TABLE 1 Effect of the different assumed values of $\mathrm{km}$ on deductions

\begin{tabular}{ccccc}
\hline $\begin{array}{c}\text { Assumed } \\
\mathrm{d} \mathrm{km}\end{array}$ & $\begin{array}{c}\text { Deduced } \\
\mathrm{Ng}\end{array}$ & $\begin{array}{c}\text { Values } \\
\mathrm{N}_{c} / \mathrm{Ng}\end{array}$ & \multicolumn{2}{c}{ Cloud flashes counted } \\
\hline 0 & 6500 & 1.9 & 12524 & V04 \\
\hline 1 & 5750 & 2.3 & 13160 & 11538 \\
2 & 5150 & 2.7 & 13795 & 12132 \\
3 & 4500 & 3.2 & 14432 & 12723 \\
4 & 3800 & 4 & 15075 & 13322 \\
5 & 3150 & 5 & 15715 & 13920 \\
6 & 2500 & 6.5 & 16361 & 14519 \\
6.67 & 2134 & 8 & 16764 & 15124 \\
7 & 2000 & 8.5 & 17002 & 15524 \\
8 & 1250 & 14 & 17644 & 16301 \\
9 & 500 & 36.5 & 18286 & 16932 \\
\hline
\end{tabular}

It is worthwhile noticing that whatever value is assumed for $\mathrm{d} \mathrm{km}$, the $\mathrm{VO} 3$ is estimated to count only about 8 percent more intra-cloud flashes than the VO4. Using the arguments presented in paper, ${ }^{6}$ these results emphasize the presence of strong and sharp current bursts in intra-cloud flashes, much sharper than mentioned in the review paper by Brook and Ogawa. ${ }^{4}$

\section{The V10 Lightning Flash Counter}

Like the VO3 and the VO4 described in the paper, ${ }^{6}$ the V10 was also designed by E. Pisler of the Institute for High Voltage Research, Uppsala.

The V10 was designed to give almost the same performance characteristics as the Anderson RSA 10 counter. ${ }^{1}$ The great advantage of the Pisler counters is that all three of them, the VO3, the VO4 and the V10 use the identical vertical antenna. Like the VO4, the V10 has its maximum sensitivity at $10 \mathrm{KHz}$, and its frequency response pattein closely follows that of the VO4. The only difference is that the threshold counting voltage amplitude at $10 \mathrm{KHz}$ of the V10 is 42.45 Volt whereas that of the VO4 is 15.1 Volt.

\section{The expected counting patterns of a V10 and VO4 when operated together}

From the counting efficiency curves for the V04 for ground flashes shown in figure 1 , it is easy to deduce what the corresponding curves for the V10 should be. The V10, like the VO4, will count ground flashes through the radiation field ${ }^{6}$ which could be taken to drop off in inverse proportion to the distance. The counting efficiency curves for ground flashes for the V10 should then be obtained from the curves for the VO4, merely by reducing the distance $\mathrm{D} \mathrm{km}$ on the abscisssa by a factor $15.1 / 42.5$. 
This is shown in Figure 2, where for ease of calculation without altering the results significantly, the efficiency curve for the V10 for Colombo has been taken to be 1 up to $5.25 \mathrm{~km}$ instead of $5.36 \mathrm{~km}$, the elbow of the curve where the efficiency is 0.1 has been placed at $15 \mathrm{~km}$ instead of at $16.36 \mathrm{~km}$, and the maximum $\mathrm{D}$ value of the curve at $30 \mathrm{~km}$ instead of at $28.46 \mathrm{~km}$.

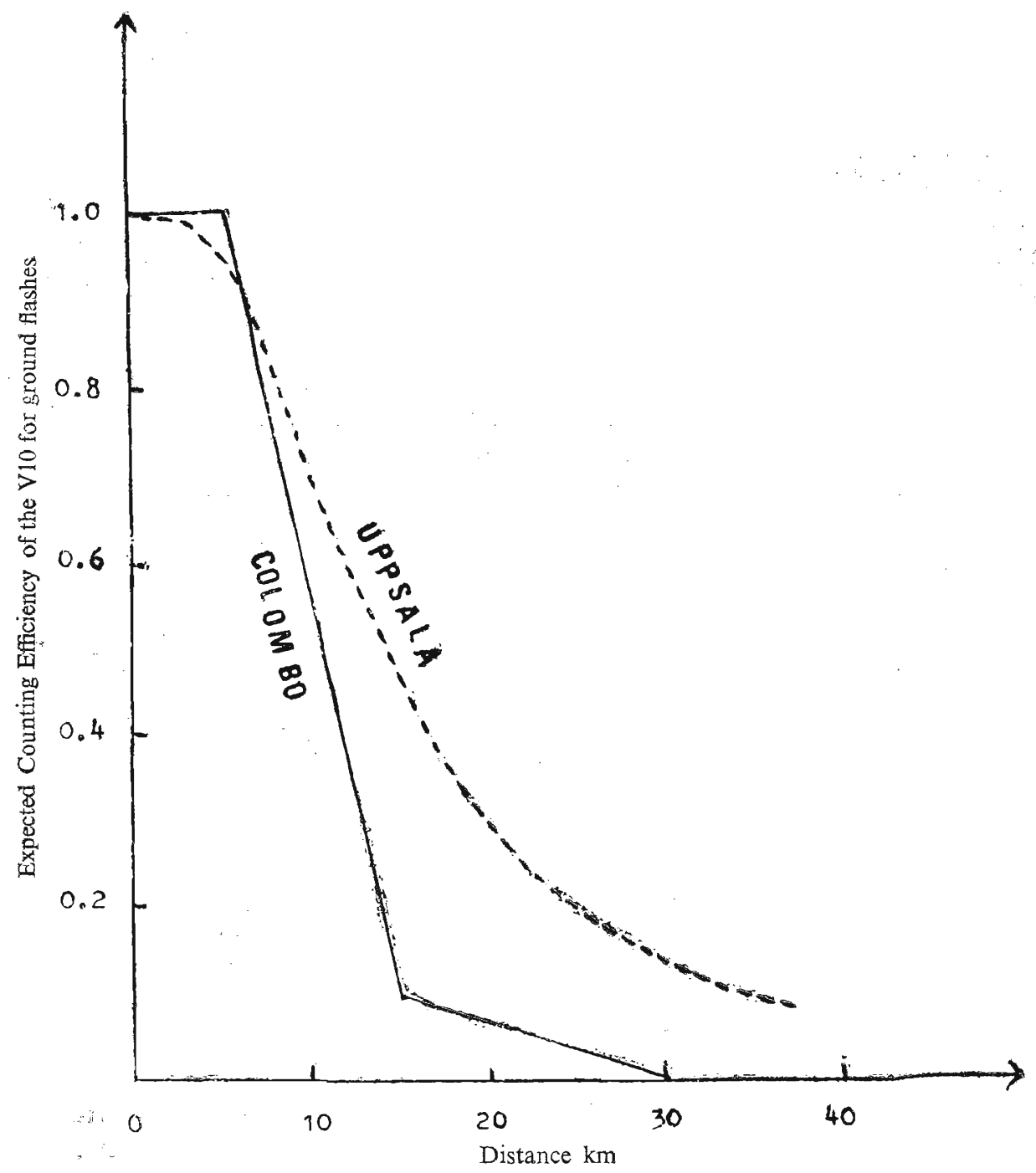

Figure 2. The expected counting efficiency curves for ground flashes af a v10 lightning flash counter for Colombo and Uppsala. 
The Uppsala curve appears to be consistent with the counting efficiency curve deduced by Anderson and his group in South Africa for the RSA 10 counter. $^{2}$ Thus there is a discrepancy in the counting efficiency curve deduced fron the counting data obtained in Colombo in the tropics, and from experiments performed in temperate zone regions. A test of the accuracy of the Colombo data is given in the experiment described in the next section.

According to the information presently available about intra--cloud lightning which was summarised by Brook and Ogawa ${ }^{4}$, the counters can only be triggered by intra-cloud flashes by positive ramp type voltage pulses with a rise time of $t_{m} \mu s$ and a voltage amplitude of $\mathrm{V}$ volt, produced by fast current pulses which exist in intra-cloud lightning strokes. The counting patterns obtained for a VO3 and a VO4 when operated together were explained on this basis. ${ }^{6}$ The V03 is more sensitive to these ramp type electro-static field changes than the VO4. However the difference in sensitivity becomes less and as the rise time, $\mathrm{t}_{\mathrm{m}} \mu \mathrm{s}$, becomes smaller and smaller.

It was found ${ }^{6}$ that the VO3 counts only about 8 percent more intra-cloud flashes than the VO4, indicating that the range of the VO3 to intra-cloud flashes occurring in the Colombo region of Sri Lanka is only slightly more than the range of the VO4. It was argued ${ }^{6}$ that there had to be current pulses in intra-cloud flashes which discharged quantities of electricity of the order of $2 \mathrm{C}$ in times of at most $200 \mu \mathrm{s}$, preferably less.

In the V10 counter, since its counting threshold is about three times higher than that of the $\mathrm{VO} 4$, for the same rise time, $\mathrm{t}_{\mathrm{m}} \mu \mathrm{s}$, it will need a higher voltage amplitude $\mathrm{V}$ to be triggered than the VO4. The triggering voltage amplitudes, $\mathrm{V}$, of ramp pulses with different rise times, $\mathrm{t}_{\mathrm{m}} \mu \mathrm{s}$, for the VO4 and V10 are given in Table 2.

TABLE 2. Triggering voltages of the counters for different $t_{m} \mu_{\mathrm{s}}$

\begin{tabular}{|c|c|c|}
\hline \multirow[t]{2}{*}{$t_{\mathrm{m}} \mu \mu_{\mathrm{s}}$} & Triggering & $\mathrm{V}$ volt \\
\hline & V04 & V10 \\
\hline 0 & 17.7 & 49.8 \\
\hline 16 & 17.7 & 49.8 \\
\hline 60 & 22 & 62 \\
\hline 100 & 38 & 107 \\
\hline 200 & 60 & 169 \\
\hline 500 & 114 & 320 \\
\hline 1000 & 180 & 506 \\
\hline
\end{tabular}

A positive ramp electrostatic pulse of this type is only expected from an intra-cloud discharge, if the discharge is within the neutral point distance, $D_{n}$, defined in the paper. ${ }^{6}$ Evidence was presented in that paper that $D_{n}$ is not more than $10 \mathrm{~km}$. Also, it was shown that the range of the VO4, for counting intra-cloud flashes, should be in the region of $9 \mathrm{~km}$. 
In the subsequent analysis, a representative picture will be used, where it will be considered that a VO4 LFC will count all intra-cloud flashes within a range of $9 \mathrm{~km}$. Also, a simplified picture, considered to be appropriate in the tropics, that an intra-cloud flash, on an average, will neutralise a representative vertical electrical dipole with a negative charge pocket at an altitude of $5 \mathrm{~km}$ and a positive charge pocket at an altitude of $10 \mathrm{~km}$ will be used. A similar simplified picture was used in the analysis of the previous experiment. ${ }^{6}$ On this picture, if the range of the V04 for counting intra-cloud flashes is taken as $9 \mathrm{~km}$, then the range of the V10 for counting intra-cloud flashes works out to be about $7.5 \mathrm{~km}$.

If the same value of $\mathrm{N}_{c} / \mathrm{N}_{\mathrm{g}}$ of 8.5 deduced in the analysis presented in the paper ${ }^{6}$ is used, and also the same arguments and assumptions presented in that paper 6 are utilised, from the expected counting efficiency curve of the V10 for Colombo, shown in Figure 2, it is easy to deduce the ratio of counts VO4/V10, averaged for various types of thunderstorms occurring over an year, for different assumed values of $\mathrm{d} \mathrm{km}$, the distance of nearest approach of the thunderstorm to the counters. If $\mathrm{d}$ is within $10 \mathrm{~km}$, then on the assumptions made, thunder should be heard distinctly at the site of the counters and the CS would be 1 . Table 3 shows the results of such an analysis.

TABLE 3. Expected ratios VO4/V10 for different assumed values of $\mathrm{d} \mathrm{km}$.

\begin{tabular}{ccc}
\hline $\mathrm{d} \mathrm{km}$ & $\mathrm{V} 04 / \mathrm{V} 10$ & $\mathrm{CS}$ \\
\hline 0 & 1.5 & 1 \\
2 & 1.6 & 1 \\
5.75 & 2.6 & 1 \\
6 & 2.8 & 1 \\
6.5 & 3.4 & 1 \\
7 & 4.7 & 1 \\
7.5 & 8.7 & 1 \\
9 & 7.3 & 1 \\
10 & 8.8 & 1 \\
\hline 12 & 12.5 & $>1$ \\
15 & 20.3 & $>1$ \\
20 & 34.0 & $>1$ \\
25 & 92.5 & $>1$ \\
\hline
\end{tabular}

\section{Experimental details}

Essentially, the same experiment, as described in the paper6, was repeated with a V10 LFC replacing the VO3 LFC.

The data were collected over a continuous period of one year from the 1 st July 1981 to the 30th June 1982. A different set of aural observers of $\mathrm{T}$ was used. There were more observers located closer to Colombo. The more distant observers were dispensed with. Many of the aural observers of $T$ used in the earlier experiment, ${ }^{6}$ were not available for this experiment. 
The locations of the aural observers of $T$ in this experiment are shown in Figure 3. It should be noted that the numbers assigned to the observing stations in this experiment do not correspond to the station numbers given in the previous experiment. ${ }^{6}$

Only stations 1,2 and 3 of this experiment correspond to stations 1,2 and 3 of the previous experiment. Also stations 5 and 7 of this experiment are the same as stations 4 and 5, respectively, of the previous experiment. In both experiments, station 1 is Colombo, where the counters were sited.

\section{The Experimental Data}

The counting data were analysed on a three-hourly basis in the same manner as the counting and $\mathrm{T}$ data were analysed in the previous experiment. ${ }^{6}$ The results of this analysis are given in a comprehensive manner in Table 4.

TABLE 4. Counting data of the present experiment

\begin{tabular}{|c|c|c|c|c|c|c|c|c|c|}
\hline 1 & 2 & 3 & 4 & 5 & 6 & 7 & 8 & 9 & 10 \\
\hline \multirow{2}{*}{$\begin{array}{l}\text { Station } \\
\text { number }\end{array}$} & \multirow{2}{*}{$\begin{array}{l}\text { distance } \\
\mathrm{km} \\
\text { Effective }\end{array}$} & \multirow{2}{*}{$\begin{array}{l}\text { Number } \\
\text { of three- } \\
\text { hour } \\
\text { periods } \\
\text { reporting } \\
T\end{array}$} & \multirow{2}{*}{$\begin{array}{l}\text { Number } \\
\text { of three- } \\
\text { hour } \\
\text { periods } \\
\text { station } \\
\text { CS }\end{array}$} & \multicolumn{2}{|c|}{$\begin{array}{l}\text { Total counts } \\
\text { for the year } \\
\text { when CS }\end{array}$} & \multicolumn{2}{|c|}{$\begin{array}{l}\text { Average counts } \\
\text { per three-hour } \\
\text { period when CS }\end{array}$} & \multirow[t]{2}{*}{$\begin{array}{l}\text { Ratio } \\
\text { VO4/V10 }\end{array}$} & \multirow{2}{*}{$\begin{array}{c}\text { Column } 7 \\
\text { standar- } \\
\text { dised by } \\
30.8 / 41.9\end{array}$} \\
\hline & & & & V04 & V10 & V04 & $\overline{V 10}$ & & \\
\hline 1 & $?$ & 186 & 186 & 22281 & 4052 & 125.2 & 21.8 & 5.7 & - \\
\hline 2 & 11.6 & 206 & 53 & 2220 & 123 & 41.9 & 2.3 & 18 & 30.8 \\
\hline 3 & 14.4 & 215 & 88 & 3358 & 88 & 38.2 & 1.0 & 38 & 28.1 \\
\hline 4 & 16.7 & 205 & 68 & 2213 & 54 & 32.5 & 0.79 & 41 & 23.9 \\
\hline 5 & 24.5 & 194 & 68 & 1519 & 14 & 22.3 & 0.25 & 109 & 16.4 \\
\hline 6 & 24.8 & 207 & 101 & 1437 & 11 & 14.2 & 0.11 & 131 & 10.4 \\
\hline$?$ & 29.1 & 176 & 63 & 632 & 6 & 10.0 & 0.10 & 105 & 7.4 \\
\hline 8 & 29.1 & 220 & 117 & 448 & 3 & 3.8 & 0.03 & 149 & 2.8 \\
\hline 9 & 29.8 & 234 & 38 & 146 & 1 & 3.8 & 0.03 & 146 & 2.8 \\
\hline 10 & 33.4 & 264 & 111 & 187 & 0 & 1.7 & 0 & - & 1.3 \\
\hline 11 & 37.2 & 250 & 59 & 89 & 0 & 1.5 & 0 & - & 1.1 \\
\hline 12 & 42.5 & 257 & 20 & 31 & 0 & 1.6 & 0 & - & 1.2 \\
\hline 13 & 43.0 & 331 & 31 & 34 & 0 & 1.1 & 0 & - & 0.8 \\
\hline 14 & 46.7 & 379 & 77 & 26 & 0 & 0.34 & 0 & - & 0.3 \\
\hline 0 & - & 0 & 1838 & 622 & 0 & - & - & - & - \\
\hline
\end{tabular}



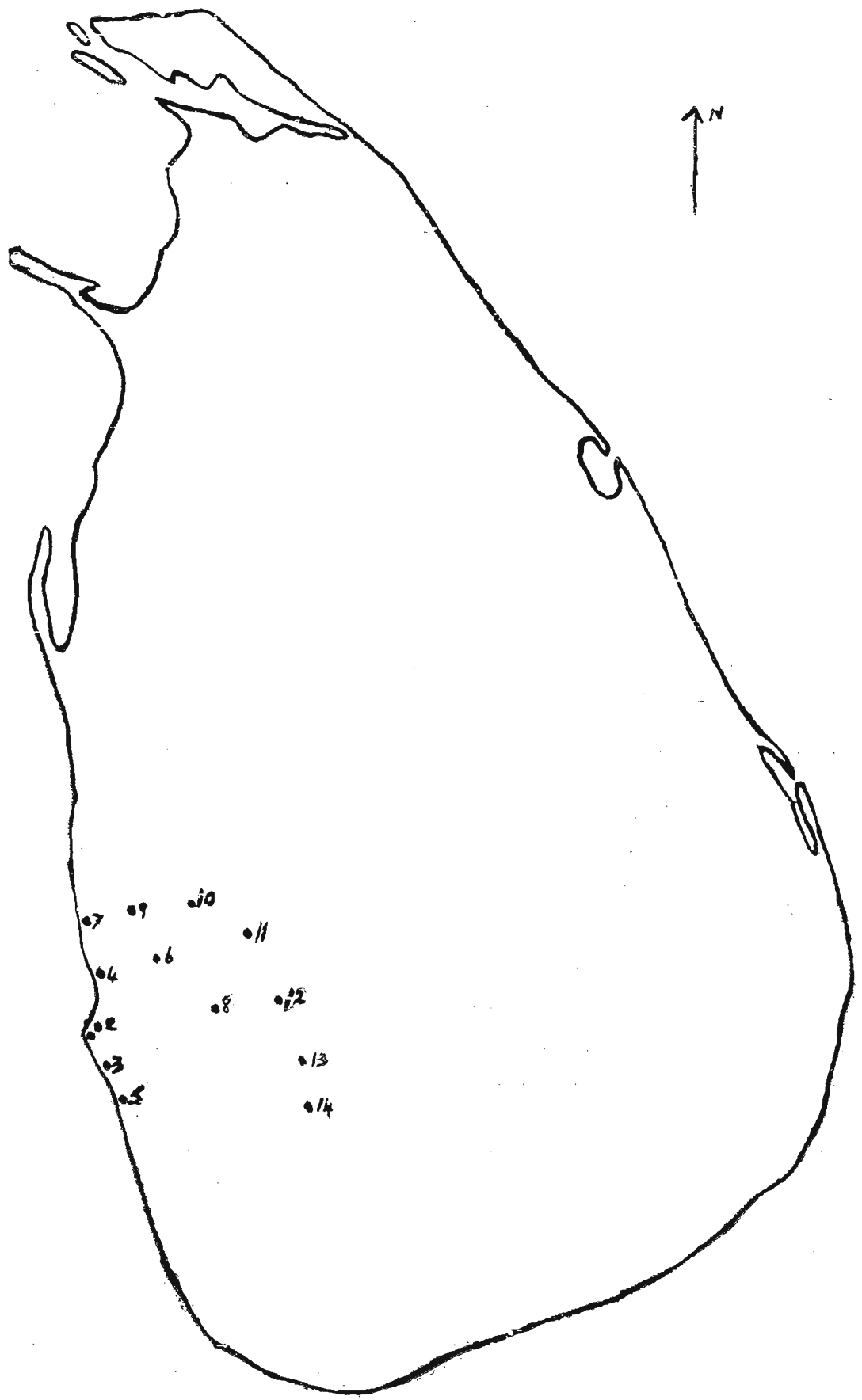

Figure 3. The location of the aural observers of thunder 
During the 186 three-hourly counting periods when the CS was 1, taking all counts into account, the ratio of VO4/V10 is seen to turn out to be 5.7. Table 5 shows how this ratio changes for different three-hourly counting levels of the V10 when the CS was still 1.

TABLE 5. Counting ratios VO4/V10 obtained for different courting levels of the V10

\begin{tabular}{rrrrr}
\hline $\begin{array}{c}\text { Counting } \\
\text { level of the } \\
\text { V10 pe } \\
\text { three-hour } \\
\text { period }\end{array}$ & $\begin{array}{c}\text { Number of } \\
\text { three-hour } \\
\text { periods }\end{array}$ & $\begin{array}{c}\text { Total } \\
\text { counts on } \\
\text { the VO4 }\end{array}$ & $\begin{array}{c}\text { Total } \\
\text { counts on } \\
\text { the V10 }\end{array}$ & $\begin{array}{c}\text { Ratio } \\
\text { VO4/V10 }\end{array}$ \\
\hline 0 & 186 & 23281 & 4052 & 5.7 \\
10 & 87 & 18334 & 3278 & 5.6 \\
25 & 37 & 11718 & 2531 & 4.6 \\
50 & 37 & 11718 & 2531 & 4.6 \\
50 & 17 & 7520 & 1839 & 4.1 \\
75 & 9 & 5032 & 1331 & 3.8 \\
100 & 5 & 3505 & 979 & 3.6 \\
\hline
\end{tabular}

The higher the counting level of tha V10, on an average, the closer should the thunderstorm have approached the counters. The experimental values of Table 5, should be compared with the predicted values of the ratio given in Table 3 , for different values of $\mathrm{d} \mathrm{km}$. The choice of $\mathrm{d}-6.67 \mathrm{~km}$ taken in the paper ${ }^{6}$, appears to be satisfactory. See also, the last paragraph of this section.

An important test of consistency between the two Sri Lanka experiments, is to compare the way in which the average counts per period of the V04 reduces with the distance of the CS reporting $\mathrm{T}$ in the two experiments.

As in the previous experiment, ${ }^{6}$ it will be assumed that when the CS is not 1 , then all the counts are due to ground flashes. Compare column 7 of table 4 of this paper with column 9 of table 1 of the paper. ${ }^{6}$ It will be seen that in the present investigation, the average counts per three-houn period on the V04 when the CS is 2 is 41.9 . whereas the corresponding figure in the previous experiment was 30.8 . Station 2 was the same in both experiments, at an effective distance of $11.6 \mathrm{~km}$. It should be remembered that in the previous experiment, station 2 was used as the standardising station in drawing the curves figures $3(\mathrm{a})$ and $3(\mathrm{~b})$ of the paper. ${ }^{6}$ In this experiment too, the results will be standardised to the counting level at station 2 in the previous experiment. This has been done in column 10 of table 4 of this paper, where the figures in column 7 of the same table have been multiplied by a factor 3.08/41.9. 
Figure 4 of this paper is merely figure $3(b)$ of the paper ${ }^{6}$ eproduced, with the standardised counting rates of this experiment, shown in column 10 of table 4, superposed. There is no doubt that the results of the two experinents are compatible and this experiment gives added support to the counting efficiency curve for ground flashes for the V04 deduced for lightning in the region of Colombo and shown in Figure 1.

A glance at column 8 of table 4 , will also indicate that the experimental data supports the expected counting efficiency curves for the V10 for Colombo as deduced from the efficiency curves of the V04 deduced from the Colombo data, better than the expected curve deduced from the Uppsala data.

A comparison of $\mathrm{N}_{g}$ and $\mathrm{N}_{c} / \mathrm{N}_{g}$ as deduced from the two Sri Lanka experiments is also instructive. In the first experiment, where the counters were operated from the 1st March 1979 to the 29th February 1980, it was deduced ${ }^{6}$ that $N_{c} / N_{g}$ was of the order of 8.5 and that $\mathrm{N}_{\mathrm{g}}$ was about 6.5 per $\mathrm{km}^{2}$ per year. (An error in the paper ${ }^{6}$ where this figure has been printed as 0.65 is regretted).

In the experiment described in this paper, where the counters were operated from the 1st July 1981 to the 30th June 1982, using the V04 counting data and the same reasoning as before, ${ }^{6}$ it can be deduced that $\mathrm{N}_{\mathrm{c}} / \mathrm{N}_{\mathrm{g}}$ is about 9.5 and $\mathrm{N}_{\mathrm{g}}$ about 4.5 per $\mathrm{km}^{2}$ pir year. Variations in thunderstorm activity from year to year are to be expected. The $\mathrm{N}_{\mathrm{g}}$ figures are comparable with those obtained by Andersion et $\mathrm{al}^{2}$ in Pretoria, South Africa but the $\mathrm{N}_{\mathrm{c}} / \mathrm{N}_{\mathrm{g}}$ figures for Colombo are much higher, the South African estimates being about 2.5. For a meaningful figure of $N_{c} / N_{g}$ and $\mathrm{N}_{\mathrm{g}}$ in a given locality, an average over a large number of years should be taken. It has been suggested 2 that, at least, an average over a 11 year sunspot cycle should be used.

Another point of interest is that the ratio $\mathrm{N}_{c} / \mathrm{N}_{\mathrm{g}}$ also need not remain the same from year to year. If the $\mathrm{N}_{\mathrm{c}} / \mathrm{N}_{\mathrm{g}}$ value of 9.5 obtained from the V04 counts in this experiment is used to compute the expected counting ratio V04/V10 for various assumed values of $\mathrm{d} \mathrm{km}$, instead of the value 8.5 obtained from the counts obtained in the previous experiment ${ }^{6}$, the expected ratios V04/V10 shown in Table 3 will increase. For example for $\mathrm{d}=7 \mathrm{~km}, \mathrm{V04} / \mathrm{V} 10$ would increase from 4.7 to 5.4 , which is closer to the experimental value of 5.7 . 


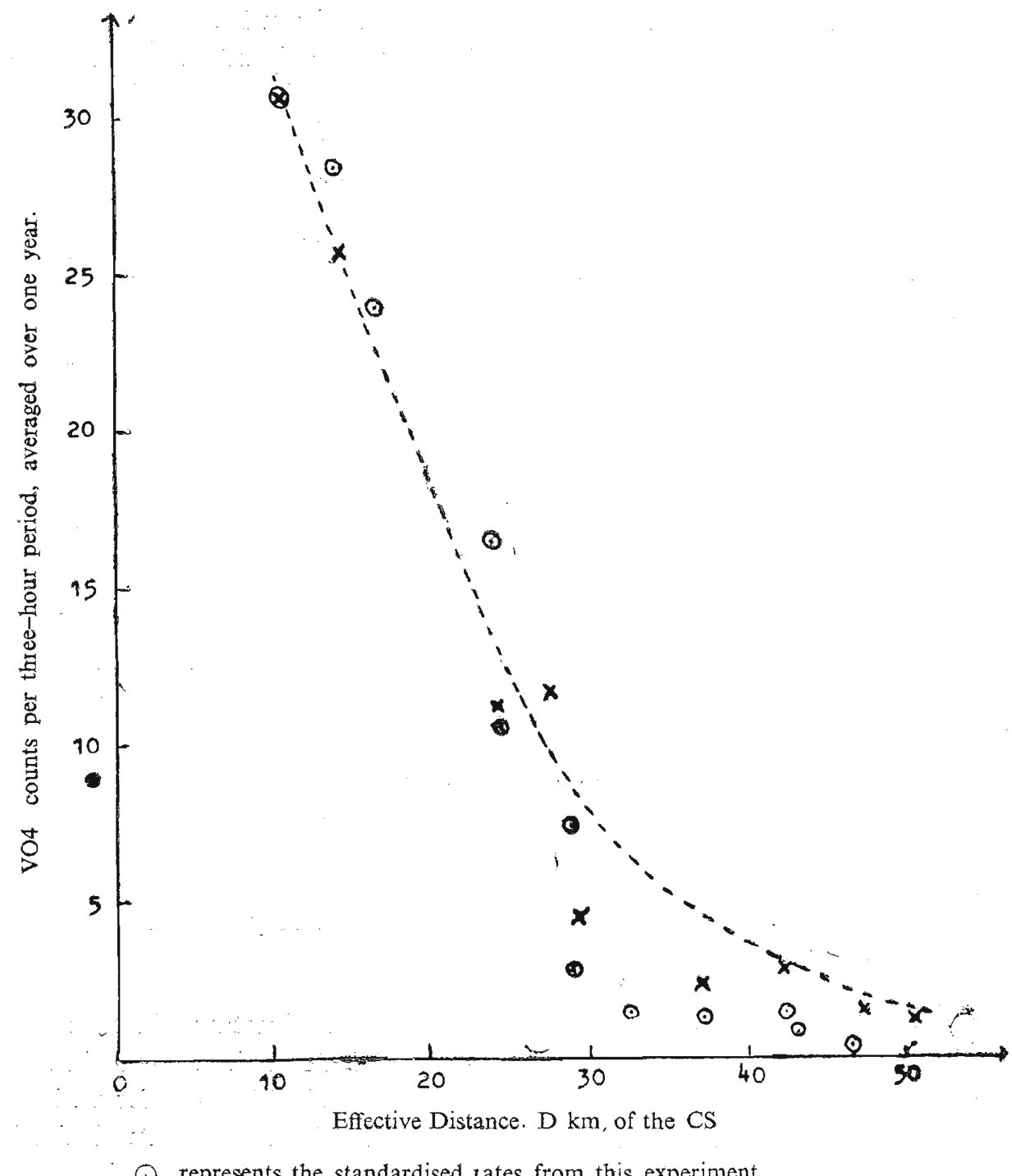

$\odot$, represents the standardised rates from this experiment,

The curve and the points marked $X$, are the same as the curve and points of figure $3(b)$ of paper. 6

Figure 4. The yearly average counts per three-hour period of the V04 for ground flashes, as a function of the distance of the CS, standardised to the value obtained for station 2 in the experiment described in the paper 6 . 


\section{Discussion}

The results of the experiment described in this paper have been shown to be consistent with those of the previous experiment. ${ }^{6}$ It is shown that the counting efficiency curves for ground flashes, as a function of distance, obtained for the V04 and V10 counters in Colombo, Sri Lanka, in the tropics, show a difference with similar curves obtained in Uppsala, Sweden, and in South Africa, which are in temperate latitudes. The methods employed were quite different.

In the two experiments performed in Sri Lanka, every single count registered by the counters over a period of one year, in each experiment, has been taken into account in the analysis. But the location of the lightning, which triggers the counter's, has been estimated only roughly, using aural reports of thunder from a team of observers.

In the other determinations, much more sophisticated lightning location systems have been used, but only selective samples have been used. The South African group, for example, has used video camera techniques 2 but their observations have been restricted to samples of night time lightning taken over a period of many years. Furthermore, their observations were made on a plateau at an altitude of about $1000 \mathrm{~m}$ above sea level. In the Uppsala determination, a Krider type LLS has been used to locate the lightning simultaneously with a record of the field change produced by it. Whether the counter would have been triggered or not by the observed field change, has been determined by a circuit analysis of the counter. In this manner, the distribution of field changes obtained as a function of distance, has been used to estimate the counting efficiency of the V04 at various distances.

From this the efficiency curve for the V10 was deduced and this agreed with the efficiency curves obtained for the RSA 10 counter by the South African group. This agreement cannot be ignored and it must be accepted that the efficiency curves given by these two groups does represent a true picture of that obtained in temperate latitudes.

On the other hand, the Sri Lanka results too cannot be ignored, although the techniques used could almost be classed as belonging to the old string and sealing wax era, which nevertheless produced excellent insight into what was happening in many instances. The internal consistency of the Sri Lanka data merits that they be taken seriously.

If the discrepancy in the counting efficiency curves obtained in Colombo, in the tropics, and in the other stations in temperate latitudes is a true effect; then what it means physically is that in the tropics, or at least in the region around Colombo, the proportion of lightning ground strokes cariying large peak currents, $I_{p}$, is much less than in temperate and possibly higher latitudes.

F-6 18510 
It was shown ${ }^{6}$ that the Colombo data is consistent with a minimum $I_{p}$ of about $6.5 \mathrm{kA}$ in first return ground strokes. The counting efficiency curves obtained in Colombo then indicate that less than 50 percent of lightning first return strokes would carry an $I_{p}>15 \mathrm{kA}$, and probably not more than 25 percent would have an $I_{p}>20 \mathrm{kA}$. The curves also suggest that not more than about 1 percent would carry an $I_{p}$ of the ordel of $100 \mathrm{kA}$.

This distribution is quite different to that given by Berger et $\mathrm{al}^{3}$ for temperate zone lightning. They estimate that at temperate latitudes, 95 percent of first return strokes have $I_{p}>14 \mathrm{kA}, 50$ percent have $I_{p}>30 \mathrm{kA}$ and 5 percent have $I_{p}>80 \mathrm{kA}$. The Uppsala and South African counting efficiency curves could more or less be predicted from the figures given by Berger et al. ${ }^{3}$

The question that now emerges is whether the $I_{p}$ distribution need be the same in the tropics as the distribution given by Berger et $\mathrm{al}^{3}$. The author can see no a priori reason why this should be so. The cloud heights and lightning channels are longer in the tropics and the $\mathrm{N}_{\mathrm{c}} / \mathrm{N}_{\mathrm{g}}$ ratios are much higher. This is an important question, not only from the pure physics point of view, but practically, for electrical and telecommunication engineers. No reliable information is available for tropical lightning and engineers tend to use data obtained from literature valid for temperate zone lightning. As the two experiments described in the paper ${ }^{6}$ and this paper indicate, this data may not be valid for Sri Lanka. It is therefore very necessary that these investigations be continued in Sri Lanka, using more sophisticated apparatus and techniques.

\section{Acknowledgements}

As in the previous experiment, ${ }^{6}$ the counters used in this experiment were gifted by the Institute for Higher Voltage Research, University of Uppsala, through the International Seminars of the University of Uppsala.

Also, as in the previous experiment ${ }^{6}$, the counters were installed in the grounds of the Sri Lanka Meteorological Department, Colombo.

The author is grateful to the Director of the Department, at the time this experiment was carried out, Mr. Ian de Mel, and his staff for the excellent coopuration given.

The author expresses his sincere thanks to Mr. K. R. Abhayasinghe Bandara for organising the readings of the counters and the team of aural observers of thunder and for collecting and checking the data obtained from them. Unfortunately Mr. Abhayasinghe Bandara could not participate in the analysis of the experiment since he left Sri Lanka on a scholas ship abroad, soon after the collection of the data.

In this experiment too, the local expenses were met by a research grant from the Natural Resources, Energy and Science Authority of Sri Lanka, for whose cooperation the author is grateful. 
The author wishes to express his deep appreciation of the invitation extended to him to participate in the International Workshop of Lightning Detection and Applications, held in August 1982 by.Professor Stig Lundquist, the Director of the Institute for High Voltage Research, Uppsala.The author thanks Professor Lundquist for the hospitality extended to him at Uppsala and the International Seminars of the University of Uppsala: for providing the necessary travel grant.

\section{References}

1. Anderson, R.B., VAN Nierkerk, H.R\& Gertenbach, J. J. (1973) Improved Lightning Earth Flash Counters, Elec. Lett. 9, (17) pp 394-395.

2. Anderson, R.B (1982) - Communication to the Workshop on Lightning Detection and Applications, Uppsala, August 1982.

3. Berger K, Anderson R.B, \& Kroninger H. (1975) Parameters of Lightning Flashes, Electra 41. pp 23-27.

4. Brook M \& Ogawa T (1977) - The Cloud Discharge, Lightning Vol. 1 Edited by R. H. Golde, Ch.6 Publishers, Academic Press, London, New York.

3. Cooray M.G.V (1982) - Private Communication.

6. Kannangara M.L.T \& Abhayasinghe Bandara K.R. (1981) The Use of Lightning Flash Counters as a Scientific Tool to deduce some Characteristics of Lightning in Sri Lanka.

J. Natn. Sci. Coun. Sri Lanka 9, (2): 229-249.

7. Krider, P, Noggle R.C. \& UMAN M.A. (1976) A Gated Wideband Magnetic Direction Finder for Lightning Return Strokes, J. Appl. Meteor. 15: 402-405. 